\title{
FATOS ESTILIZADOS E DIÁLOGO PRÓXIMO: METODOLOGIA EM GEOGRAFIA ECONÔMICA*
}

\author{
Gordon L. Clark ${ }^{* *}$ \\ University of Oxford
}

Resumo: Uma diferença entre os economistas e os geógrafos é o significado atribuído pelos primeiros aos fatos estilizados e o significado bem diferente atribuído pelos últimos à diversidade da vida econômica. Este estudo inicia-se por essa distinção e argumenta que os fatos estilizados subjugados à teoria de Krugman pode empobrecer a inovação teórica na geografia econômica, da mesma forma que a hipótese sobre os mercados eficientes teve consequências dramáticas para a pesquisa econômica. Uma alternativa para a os fatos estilizados subjugados à teoria é sugerida, levando-se em consideração a relação inevitável e contrária existente entre a teoria e a observação empírica. A minha perspectiva filosófica não é nem fundadora e nem pós-moderna, mas é, em vez dessas, uma versão do ceticismo filosófico. Após estudar os avanços mais recentes da geografia econômica, as alegadas virtudes da objetividade e os supostos riscos da subjetividade são desafiados. Nossa hipótese é a de que as ditas virtudes da primeira estejam contaminadas pela crença em um mundo já pronto e estático e que os riscos da segunda sejam exagerados pela crença em uma verdade incontestável. Essa é a base da defesa das virtudes do diálogo próximo na geografia econômica e, em particular, na geografia das finanças.

Palavras-chave: Diálogo próximo. Geografia econômica. Economia. Ceticismo. Fatos estilizados.

\section{STYLIZED FACTS AND CLOSE DIALOGUE: METHODOLOGY IN ECONOMIC GEOGRAPHY}

Abstract: One difference between economists and geographers is the significance attached by the former to stylized facts and the very different significance attached by the latter to the diversity of economic life. The paper begins with this distinction and argues that Krugman's theoryenslaved stylized facts may impoverish theoretical innovation in economic geography just as the efficient-markets hypotheis has had severe consequences for research in finance. An alternative to theory-enslaved stylized facts is suggested, noting the inevitable and antagonistic relationship between theory and empirical observation. My philosophical perspective is neither foundational nor postmodern, but is, rather, a version of philosophical skepticism. Having reviewed recent developments in economic geography, the claimed virtues of objectivity and the supposed dangers of subjectivity are disputed. I suggest that the former is compromised by its reliance upon a ready-made world, while the dangers of the latter are exaggerated by an implied commitment to an uncontested truth. This is the basis for arguing the virtues of close dialogue in economic geography and in the geography of finance in particular.

Keywords: Close dialogue. Economic geography. Finance. Skepticism. Stylized facts.

\section{HECHOS ESTILIZADOS Y DIALOGO CERCANO: METODOLOGÍA EN GEOGRAFÍA ECONÓMICA}

Resumen: Una diferencia entre los economistas y los geógrafos es el significado atribuido por los primeros a los hechos estilizados y el significado biendiferente atribuido por los últimos a la diversidad de la vida económica. Este estudio se inicia por esa distinción y argumenta que los hechos estilizados subyugados a la teoría de Krugman pueden empobrecer la innovación teórica en la geografía económica, al igual que la hipótesis sobre los mercados eficientes tuvo consecuencias dramáticas para la investigación económica. Una alternativa a los hechos estilizados subyugados a la teoría es sugerida, teniendo en cuenta la relación inevitable y contraria existente entre la teoría y la observación empírica. Mi perspectiva filosófica no es ni fundadora ni postmoderna, pero es, en vez de ellas, una versión del escepticismo filosófico. Después de estudiar los avances más recientes la geografía económica, las supuestas virtudes de la objetividad y los supuestos riesgos de la subjetividad son desafiados. Nuestra hipótesis es que las estas virtudes de la primera están contaminadas por la creencia en un mundo ya listo y estático y que los riesgos de la segunda sean exagerados por la creencia en una verdad incontestable. Esta es la base de la defensa de las virtudes del diálogo cercano en la geografía económica y, en particular, geografía de las finanzas.

Palabras-clave: Dialogo cercano. Geografia Económica. Economía. Ceticismo. Hechos estilizados.

*O apoio para este artigo foi providenciado pelo Australian Housing and Urban Research Institute e pelo Australian Research Council, como parte de um projeto maior sobre fundos de pensão e investimento urbano. Foi apresentado pela primeira vez em um painel organizado por Amy Glasmeier no Annual Meeting of the Association of American Geographers, em abril de 1997, na cidade de Fort Worth, Texas. Agradeço a Mike Berry, que apoiou e encorajou o projeto, bem como a Maryann Feldman, Meric Gertler e Ben Harrison, que fizeram comentários no rascunho inicial. Subsequentemente, muito me auxiliaram os comentários de John Agnew, Trevor Barnes, Philip Pettit, Amanda Root, Eric Sheppard, Nigel Thrift e os de quatro outros pareceristas. Também agradeço a Jan Magee, que, como de costume, forneceu uma excelente assistência. Apenas este autor é responsável pelas visões e opiniões aqui expressadas. 0 artigo foi publicado originalmente na revista Annals of the Association of American Geographers, n. 88(1), 1998. A revista GEOgraphia agradece a autorização do autor e da revista para traduzir o artigo original. Tradução de Frank Holbach Duarte e Gabriel Severo Curuja, sob a supervisão e a revisão da Prof. ${ }^{a}$ Dr. ${ }^{a}$ Elizamari Becker (UFRGS). Revisão técnica do Prof. Dr. Daniel Sanfelici (UFF).

**Doutor em Geografia, docente da faculdade de Geografia, Universidade de Oxford, Mansfield Rd., Oxford OX1 3TB, U.K.; E-mail gordon.clark@geog.ox.ac.uk. 


\section{Introdução}

Os trabalhos mais recentes nas áreas da geografia econômica e da geografia das finanças são baseados em entrevistas mais minuciosas ou em diálogo próximo [diálogo próximo] com interlocutores dos ramos econômicos (ver, por exemplo, CLARK, 1997; LEYSHON et al., 1998; McDOWELL, 1997; e THRIFT, 1996, cap. 6). Ao contrário de outros métodos de pesquisa empírica, o diálogo próximo baseia-se na intimidade ou proximidade dos pesquisadores com os entrevistados em um setor, um nível de comprometimento pessoal em desacordo com as noções convencionais de distanciamento e objetividade científicos. Como Schoenberger (1991; 1996) demonstrou em um contexto relacionado, o diálogo próximo pode envolver relações complexas entre entrevistadores e entrevistados. Logo, o diálogo próximo é uma metodologia de pesquisa de estudo de caso que usa entrevistas estruturadas e não estruturadas no contexto da relação entre pares para revelar a verdadeira lógica por trás da tomada de decisão. No campo da economia e da "nova" geografia econômica defendida por Paul Krugman, fatos estilizados - tais como a suposta persistência de regiões industriais - dominam o raciocínio intelectual. Para Krugman (1991), os fatos estilizados são escravos de argumentos teóricos sobre a verdadeira lógica da geografia econômica'. Embora nem todos os geógrafos econômicos utilizem ou mesmo aceitem o uso do diálogo próximo, a importância atual atribuída ao diálogo próximo em relação aos fatos estilizados pode ser um diferencial básico entre a geografia econômica dos geógrafos e aquela dos economistas.

Neste artigo, argumento que o diálogo próximo pode desempenhar um papel importante na promoção da inovação teórica na área da geografia econômica, de forma geral, e na geografia das finanças, em particular. Como primeiro passo no argumento, observo a natureza e a prática da teorização na nova geografia econômica, reconhecendo que o trabalho de Krugman teve, e terá no futuro, implicações significativas na forma como os economistas entendem a geografia econômica - ou até mesmo na forma como muitos geógrafos praticam a geografia econômica. Isso é importante para avaliar o que pode ser distintivo sobre a geografia econômica dos geógrafos e o que pode ou não pode separar economia e geografia como disciplinas. 0 segundo passo do

${ }^{1}$ Por contraste, Kaldor (1985:8) pensava que os fatos estilizados poderiam ser utilizados para subordinar "a dedução à indução". Ele argumentava que os fatos estilizados podem ser criados a partir de "um estudo de estatística ou por meio de questionários especiais que incluam 'conversas informais com os donos ou executivos de pequenas empresas' (e eu presumo que os executivos de grandes empresas também)". No entanto, sua noção sobre fatos estilizados já foi completamente deslocada e perdida. Fui lembrado sobre a contribuição de Kaldor por John Agnew e Trevor Barnes. argumento é sugerir que dualismos como teoria versus observação empírica (ou dedução versus indução) podem ser praticamente resolvidos por referência a uma noção mais filosoficamente cética em relação à construção do conhecimento. Tendo estabelecido uma forma de integrar os dois lados da equação, o artigo passa então a observar mais detalhadamente as virtudes e, especialmente, os supostos vícios do diálogo próximo. Basicamente, entendo que muitos pesquisadores são excessivamente idealistas sobre a possibilidade de verdade nas ciências sociais. Embora o diálogo próximo pareça envolver alguns papéis e relações sutis (e outros não tão sutis), defendo que a objetividade acadêmica propriamente dita só é plausível se recuarmos a uma teoria de conhecimento que idealiza fatos e retira a complexidade da vida.

Haja vista a dependência passada de dados quantitativos para a modelagem de sistemas econômicos regionais (CLARK et al., 1986) e, mais recentemente, o uso de evidências legais para analisar a estratégia corporativa (CLARK, 1993), pode parecer estranho propugnar o uso do diálogo próximo. Ao pesquisar as estratégias de investimento dos fundos de pensão anglo-americanos, tornou-se evidente para mim que a compreensão de tomada de decisão financeira foi empobrecida pela hegemonia de um fato estilizado: a afırmação, atribuída a Michael Jensen, de que a hipótese dos mercados eficientes é o fato mais bem estabelecido nas ciências sociais. Esse "fato" teve implicações profundas sobre a definição de quais seriam (ou não) questões legítimas de pesquisa (por exemplo, o papel da geografia nos mercados financeiros), quais seriam os pressupostos legítimos acerca da tomada de decisão individual (por exemplo, a importância do contexto local na tomada de decisão de investimento) e quais seriam os argumentos legítimos sobre a regulamentação (por exemplo, a possibilidade de direcionar fundos de pensões às necessidades urbanas). Da mesma forma, os fatos estilizados de Krugman ameaçam o trabalho arduamente conquistado nos últimos vinte anos, que visou à integração da heterogeneidade espacial ao núcleo teórico da geografia econômica. Se desejamos escapar da sombra projetada pela hipótese de mercados eficientes na geografia das finanças, e se defendemos uma geografia econômica rica e geograficamente informada, precisamos ser claros sobre como e por que o diálogo próximo é um método aceitável de análise.

Portanto, o argumento que desenvolvo neste trabalho tem duas vertentes interligadas. Uma faz referência ao desafio proposto por teóricos como Paul Krugman à geografia econômica que tem se desenvolvido ao longo das últimas décadas. Estamos sendo forçados a repensar 
a nosso condição e as bases de nossa alegada distinção (vide SCHOENBERGER, 1998). A segunda vertente é sobre a inovação teórica na geografia e na economia. Para fazer com que meu argumento funcione, suprimo toda a gama e a diversidade de práticas de pesquisa em economia e geografia. Resisto à tentação de argumentar a favor ou contra diferentes tipos de economia (como a economia neoclássica) e de geografia (incluindo versões relacionadas da economia política). Dow (1997) e Sayer (1995), respectivamente, dão tratamento adequado a estas literaturas. Além disso, enfatizo a prática da pesquisa em vez de seus resultados, excluindo, assim, trabalhos de geógrafos que considero favoráveis e de outros que considero contrários ao meu ponto de vista. Este artigo não tem o propósito de ser uma revisão da literatura.

Observe-se também que o meu entendimento sobre metodologia se sobrepõe e se relaciona com trabalhos recentes nos campos do feminismo, da sociologia e da antropologia, bem como da economia (para surpresa de alguns). Mais importante, o meu objetivo é mostrar que há uma estreita ligação entre os objetivos da pesquisa e o seu contexto, mesmo que não haja uma metodologia de pesquisa ideal na área das ciências humanas².

\section{Geografia Econômica e fatos estilizados}

A prática de pesquisa nas ciências sociais é bastante afetada por modas e por hábitos culturais (BARNES, 1996). Como estudantes de pós-graduação, herdamos um mundo intelectual criado por nossos orientadores e pelos orientadores de nossos orientadores, assim como somos responsáveis por ensinar às próximas gerações de estudantes a prática da pesquisa em relação aos problemas intelectuais que ajudamos a resolver. Em diversos aspectos, afastamo-nos das tradições que herdamos para criar nosso próprio estilo, assim como nossos orientadores também afastaram-se de seus próprios ambientes herdados. Se retornássemos a algumas gerações intelectuais precedentes, encontraríamos a subdisciplina da geografia econômica dominada por algumas questões básicas, incluindo a questão da convergência do crescimento econômico inter-regional e as razões pelas quais existe uma hierarquia espacial de assentamentos. Nem todos os geógrafos trabalharam com essas questões, mas elas

${ }^{2}$ Veja Martha Nussbaum (1990) sobre a conexão entre a forma e a substância do raciocínio intelectual. Também fui encorajado por seu argumento recente de que podemos utilizar todos os tipos de recursos (incluindo a literatura) para libertar nossa imaginação econômica. Ela traz esse argumento fazendo referência aos modelos improdutivos de penúria e privação que dominam a literatura na área da economia (NUSSBAUM, 1996). Conforme ficará evidente, também concordo com ela que a "imaginação literária" é tão anticientífica ou antieconômica quanto a imaginação fechada de muitos teóricos obcecados com as convenções em voga que dependem de fatos estilizados na economia e na geografia. tiveram sua importância e precisavam ser consideradas, nem que seja por sua simplicidade e coerência. A partir da década de 1990, o centro do palco passou a ser dominado por estudos de caso setoriais; a revolução quantitativa foi contornada e deslocada por um modo mais qualitativo e especulativo de análise, na esperança de representar a extensão espacial e a diversidade da vida econômica. A geografia econômica quantitativa persiste na disciplina, mas não é atualmente o modo habitual de análise, não obstante as notáveis realizações de alguns de seus praticantes (ver WEBBER; RIGBY, 1996).

O desafio para a geografia é compreender a diversidade econômica em relação a processos da mudança econômica mais abrangentes. A pesquisa de Gertler (1996; 1993) sobre a evolução do setor de máquinas na Alemanha representa o que há de melhor nesse tipo de trabalho, recorrendo ao diálogo próximo com fontes do setor para construir uma compreensão da dinâmica da indústria e de seu lugar na economia global em oposição às expectativas comuns embasadas na literatura. Gertler constrói uma imagem de baixo para cima, a partir dos detalhes obtidos com o diálogo e com o conhecimento de outras pessoas. Por outro lado, a geografia econômica de Krugman (1991) remonta a uma época anterior. Ele se preocupa com os tipos de questões que dominavam a disciplina vinte anos antes. Por que existem regiões industriais? Por que há uma hierarquia espacial persistente? Seus métodos de análise, elaborados a partir de pesquisas em economia internacional, são focados em fornecer respostas a essas perguntas, ignorando a diversidade da vida econômica em detrimento de proposições gerais formuladas em leis. Krugman utiliza fatos estilizados, como a existência de retornos crescentes de escala, combinados com seus métodos analíticos em um círculo autorreferencial: os fatos estilizados escolhidos permitem a aplicação de métodos analíticos que, desenvolvidos no estudo da economia internacional, explicam os fatos estilizados escolhidos pela geografia econômica.

Enquanto os economistas priorizaram um conjunto de questões que costumavam ser importantes para os geógrafos há algumas décadas, utilizando métodos de pesquisa que dominam a economia ortodoxa, os geógrafos afastaram-se sistematicamente dessas questões ao longo das últimas décadas com o intuito de formular questões e métodos de pesquisa diferentes ${ }^{3}$. Ambos os lados estão extremamente conscientes dessa distância. Krugman (1991) reconhece que sua análise de

${ }^{3} \mathrm{Na}$ verdade, apenas um pequeno número de geógrafos conseguiu sistematicamente preencher a lacuna e publicar nos principais periódicos de ambas as disciplinas (como o Annals e o American Economic Review). Poucos periódicos apreciam as ideias da outra disciplina e poucos parecem dispostos a considerar a contribuição excepcional em vez da contribuição padrão. O trabalho de Maryann Feldman é uma exceção importante (FELDMAN; FLORIDA, 1994; AUDRETSCH; FELDMAN, 1996), bem como o de Michael Storper (STORPER, 1989; STORPER; SALAIS, 1997). 
regiões industriais pode não agradar aos geógrafos, mas ele não está particularmente preocupado com as críticas. Sua audiência é claramente formada por economistas. Não surpreendentemente, os críticos de Krugman enfatizam sua abstração injustificada, argumentam contra a relevância das questões que ele identifica e, em geral, sugerem que suas descobertas têm pouco valor empírico, dada a diversidade geográfica dos sistemas econômicos (ver, por exemplo, MARTIN; SUNLEY, 1996). Parece claro que muitos geógrafos não aceitam os problemas idealizados de Krugman, bem como seus fatos estilizados e modos de representar os problemas da geografia econômica. Uma implicação disto é que os geógrafos trabalham melhor com a geografia econômica: uma apreciação substantiva e refinada da diversidade, combinada com os métodos empíricos de análise, como estudos de caso, é o método adequado de se trabalhar com a geografia econômica (vide GEERTZ, 1983).

Existem outras diferenças significativas entre a geografia econômica de geógrafos e a de economistas. Alguns geógrafos contestam a relevância dos modelos de equilíbrio geral, ou mesmo parcial, dos sistemas econômico-espaciais. Embora reconheçam as semelhanças desses modelos com técnicas analíticas e matemáticas, há uma suspeita de que a elegância e a facilidade de tratamento analítico orientam o foco da análise, em lugar dos problemas empíricos. Em suma, os geógrafos contestam a plausibilidade de premissas como a de informações homogêneas, custos de transação e de ajuste limitados e a suposição de convergência espacial-econômica (CLARK et al, 1986). Krugman está ciente desses temas e fez contribuições significativas através da aplicação de modelos de concorrência imperfeita aplicados ao comércio para compreender as propriedades dinâmicas de sistemas econômicoespaciais. Ainda assim, muitos geógrafos se espantam com a suposição da convergência econômico-espacial com foco em equilíbrio, evidente em estudos recentes dos economistas sobre crescimento inter-regional (compare-se MARTIN; SUNLEY, 1997, com BARRO; SALAI-MARTIN, 1994). Há, também, certo desconforto com as implicações dos modelos de convergência econômicoespacial para as políticas públicas. A suposição de convergência nega o valor (ou a necessidade) dos programas de desenvolvimento econômico local e nega a segmentação espacial e funcional dos mercados de trabalho estruturados por discriminação de raça e de gênero.

Nem todos os economistas compartilham do comprometimento com o esteticismo metodológico (ver WOOLLEY, 1993) ou com os princípios de convergência (ver NELSON, 1995), e nem todos os economistas estão desinteressados no futuro da população urbana pobre. Hahn (1991) e Baumol (1991), que fizeram suas reputações usando métodos matemáticos e (no caso de Hahn) análises de equilíbrio geral, perguntamse se a preferência pela elegância e facilidade de tratamento é justificável. Eles questionam a relevância e a plausibilidade de diversas pesquisas econômicas e sugerem que a responsabilidade social exige uma reavaliação da prioridade a métodos matemáticos e modelos que empobrecem o alcance do compromisso e da imaginação econômica. Fazendo coro a esses temores, Romer (1994) critica a própria pesquisa anterior sobre modelos de crescimento de capital, sugerindo que a pesquisa foi comprometida pelas práticas aceitas de teoria macroeconômica e, como consequência, não reconheceu as questões mais importantes, embora menos analiticamente tratáveis, relativas ao crescimento endógeno. Mais significativamente, Basu e Fernald (1997) demonstram que as evidências sobre retornos crescentes de escala na produção dos EUA é menos robusta do que se supõe. Os autores encontraram "heterogeneidade substancial entre os setores" e "evidências de retornos decrescentes de escala". Eles também atacam o que chamam de "parábolas", como a dos retornos crescentes de escala, apontando os problemas resultantes dessas noções simplistas para a compreensão do desempenho real da economia ${ }^{4}$.

Ao mesmo tempo, uma nova geração de economistas vem atacando os fundamentos dos modelos de equilíbrio sobre a economia. Embora se presuma que os mercados financeiros sejam os mercados mais eficientes das economias ocidentais, Shleifer (1998) e colegas demonstraram a existência de ineficiências sistêmicas ou irracionalidades. Em que pese o pressuposto generalizado de que os mercados financeiros são sistemas auto-organizados e autocorrigíveis de tomada de decisão descentralizada, o trabalho de Shleifer questiona a consistência dos processos de arbitragem. Embora se presuma que a especulação é um aspecto superficial dos mercados, parece que ela pode ser essencial para o funcionamento dos mercados financeiros. Todas essas observações são empíricas e se apoiam em detalhada análise dos padrões e processos de transação. De todas essas formas, o trabalho de Shleifer questiona a plausibilidade dos fatos estilizados de Jensen sobre os mercados financeiros e busca derrubar suposições cômodas sobre a coerência e a

${ }^{4}$ Os geógrafos têm tomado como certa a existência de retornos crescentes e de competição imperfeita (e, portanto, de dependência de trajetória; ver ARTHUR, 1994). Isso surge em uma variedade de discussões acerca do crescimento regional e dos distritos industriais, dados como referências de argumentos úteis contra ortodoxia (ver CLARK, 1994; STORPER, 1991). Entretanto, é possível que tenhamos sido involuntariamente seduzidos por Arthur e Krugman no interesse de manter a sido involuntariamente seduzidos por Arthur e Krugman no interesse de manter a
plausibilidade de alternativas para a economia neoclássica. Comparar com Harrison et al (1996). 
ordem dos sistemas econômicos. Apesar da intenção de Krugman (1996) de incorporar a diversidade da paisagem econômica em seus modelos de geografia econômica, as bases fundamentais de sua abordagem estão sendo questionadas no interior da disciplina de economia. Seus profissionais estão cada vez mais céticos sobre os fatos estilizados que têm legitimado suposições sobre a coerência dos processos econômicos em geral.

\section{Os dois lados do conhecimento}

Com certa simplicidade, pode-se supor que a questão crucial dividindo muitos economistas e geógrafos é o status conferido aos fatos estilizados subjugados à teoria em oposição a estudos de caso detalhados (e tudo o que implicam). Porém, como tenho tentado sugerir, embora essa seja uma distinção importante no que diz respeito à prática atual da geografia econômica, é também uma divisão que começou a aparecer na economia ${ }^{5}$. Pode-se supor, então, que a vitória está próxima, que o uso de fatos estilizados perderá a preferência em face da maior importância atribuída aos métodos de análise que conferem bastante valor aos detalhes da vida econômica. Isso é possível, mas improvável. Qualquer um familiarizado com a "cultura da economia" prontamente verificará a visível relutância dos profissionais da área em alterar seus métodos de análise, a despeito dos desafios impostos por pós-modernistas, feministas e outros (ver, de forma geral, DOW, 1997). Seja como for, tal vitória (se é que devemos chamá-la assim) seria inútil, dada a relação real entre os fatos estilizados e a diversidade empírica.

Para explicar, vamos observar mais detidamente a relação entre os fatos estilizados dos economistas e a diversidade empírica dos geógrafos antes de examinarmos especificamente o diálogo próximo. Por seus próprios méritos, os fatos estilizados têm três virtudes específicas. Quando integrados com a sua teoria fundamental, são um ponto de referência para avaliar a importância de observações empíricas extraídas de uma ampla variedade de circunstâncias. São também um teste da relevância das observações empíricas, estruturando o escopo da análise empírica mesmo em face de possibilidades ilimitadas. Os fatos estilizados são também uma forma de coerência comumente aceita, incentivando a investigação sistemática sobre e contra

${ }^{5}$ Um bom exemplo dessa tensão na economia pode ser encontrado no recente debate sobre a tese de Michael Porter de que altos padrões ambientais domésticos podem realmente contribuir para o sucesso de longo prazo de empresas e até mesmo para a competitividade da economia nacional. Porter e Van der Linde (1995) argumentam a partir de casos concretos. Críticos como Palmer et al. (1995) argumentam a partir da teoria, sugerindo que os imperativos teóricos vêm em primeiro lugar e que os casos são apenas parciais e inconclusivos. Qualquer que seja a evidência, a presunção é a favor de pressupostos teóricos. a ameaça de anarquia. Em outras palavras, os fatos estilizados são acreditados como essenciais para as ciências sociais, forçando os pesquisadores, se quiserem ser aceitos, a testar as suas observações empíricas com base em padrões de significância, relevância e coerência de terceiros. Assim, os fatos estilizados executam duas funções inter-relacionadas: primeiro, limitam o leque de possibilidades e, segundo, incentivam o desenvolvimento gradual de programas de pesquisas disciplinares. Nesse contexto, podemos ver como e porque a hipótese de mercados eficientes se tornou o melhor dos testes sobre a importância, a relevância e a coerência das pesquisas no campo das finanças, difundindo-se largamente e influenciando os programas de pesquisa em economia e ciências sociais nas últimas duas décadas (comparar FAMA, 1970 com FAMA, 1991).

E quanto à diversidade empírica dos geógrafos? Quais são as suas virtudes? Para os propósitos do nosso argumento, três delas podem ser prontamente identificadas. Para começar, a observação empírica é uma oportunidade de avaliar o conteúdo substantivo dos fatos estilizados e de suas teorias de origem. De certa maneira, ao utilizar estudos de casos e observações individuais para refletir sobre a profundidade ou a qualidade de fatos estilizados, em oposição à generalidade afirmada, essa forma de avaliação pode se tornar totalmente assistemática. Por outro lado, a observação empírica pode ser bastante sistemática, buscando validar ou mesmo negar fatos estilizados já estabelecidos na busca por outros fatos estilizados mais consistentes. A observação empírica é também uma oportunidade para a livre associação de imaginação e intuição, onde residem as raízes da inovação e da invenção intelectual. A esse respeito, a observação empírica é também uma medida do desenvolvimento intelectual do pesquisador, refletindo a importância comumente atribuída às nossas próprias agendas, ao contrário das agendas intelectuais herdadas de outros. Para muitos analistas e filósofos do conhecimento, a observação empírica vincula-se ao conteúdo, à inovação e à autonomia (ver discussão de McDOWELL, 1994 com referência a Davidson e Kant). $O$ ataque de Shleifer (1998) à hipótese dos mercados eficientes combina todas as três virtudes em uma tentativa de escapar de uma instituição de ciência social fechada e autorreferencial construída por outros.

Poderíamos continuar esta discussão sobre as virtudes dos fatos estilizados e da observação empírica apresentando exemplos e identificando as circunstâncias para demonstrar o valor de suas respectivas proposições. A partir da literatura da economia e da geografia, fica claro que há um intenso debate sobre o que pode ser obtido empregando-se esses métodos (ver McDOWELL, 
1992a; 1992b; SCHOENBERGER, 1992). Mas também deveria ficar evidente que, apesar de toda a discussão sobre as respectivas virtudes de ambos, os dois métodos estão unidos - eles parecem ser ao mesmo tempo separados e críticos imanentes um do outro. Seguindo John McDowell, pode-se sugerir que eles são unidos como dois pesos localizados em extremidades opostas de uma gangorra ${ }^{6}$.

Se tivéssemos de começar com a observação empírica, seríamos inevitavelmente atraídos para o outro lado da gangorra, aquele onde estão os fatos estilizados subjugados à teoria, porque precisamos da disciplina da teoria para dar sentidoàrelevância denossas observações empíricas. Do outro lado da gangorra, a começar pela teoria, os fatos estilizados nos levariam inevitavelmente à observação empírica, porque fatos estilizados sem conteúdo são exercícios estéreis e fundamentalmente irrelevantes em formalidade analítica. Nessa gangorra, com a observação empírica e os fatos estilizados separados pelos imperativos de suas respectivas práticas costumeiras, a lógica fundamental que mantém a ligação entre as duas opções metodológicas só pode ser um verdadeiro comprometimento com a curiosidade intelectual. Podemos também imaginar que as duas extremidades são interligadas por uma relação tensa, dialética, sugerindo que cada uma é a imagem espelhada da outra, embora em relação de oposição?.

Somos tentados a buscar uma resolução para esse impasse metodológico, para resolver o ato de equilíbrio em favor de um lado e não de outro, e para resolver o conflito aparentemente interminável entre as opções recorrendo a uma proposição superior e integradora. Por exemplo, os defensores de fatos estilizados alegam que a observação empírica inevitavelmente reflete a teoria, não havendo diferença real entre os dois, exceto que um está de um lado da teoria, enquanto o outro está próximo, mas do outro lado da teoria. Resumidamente, o argumento é que a observação empírica está saturada por uma ordem implícita, inevitavelmente estruturada pela teoria invisível, nunca sendo completamente livre da teoria, como às vezes alegam seus adeptos mais ingênuos. Nesse caso, dada a escolha entre iniciar pelo lado estilizado e iniciar pelo lado da observação empírica da teoria, parece melhor se começarmos pelo primeiro e, em seguida, testarmos nossos argumentos com a última. Embora aparente ser perfeitamente

${ }^{6}$ Meu uso do argumento de McDowell não deve ser interpretado como uma concordância completa com todo o seu argumento ou, nesse caso, uma versão exata da estrutura de sua metáfora. Tenho tomado liberdades com sua metáfora e os termos e a estrutura dos lados opostos da gangorra.

Em grande parte, ignoro o status teórico da argumentação dialética neste trabalho. No entanto, a minha metáfora da gangorra poderia estar relacionada ao raciocínio dialético. Veja Harvey (1996) para uma exposição notável e bastante original de raciocínio dialético. As minhas preferências filosóficas tendem à tradição analítica, em oposição à tradição continental; ver Putnam (1992). razoável, essa fórmula faz uma suposição insustentável. Ela supõe que o mundo econômico e social já está estabelecido e que o processo de teorização consiste em uma aproximação cada vez maior desse mundo préestabelecido. A respeito disso, eu diria que o verdadeiro desafio para a ciência social é dar sentido ao mundo reivindicado pelos outros, um mundo no qual teorias herdadas não parecem ser capazes de sustentar suas reivindicações de singularidade. Paradoxalmente, parece que temos muitas teorias para as observações empíricas disponíveis e bem poucas teorias que abordem a abrangência e a diversidade do mundo.

Também sou cético em relação a reivindicações de virtudes atribuídas à observação empírica. Em algumas frentes de pesquisa, fortes argumentos são aduzidos a respeito da pluralidade da observação empírica, o que sugere um compromisso de representar o mundo em toda a sua diversidade e variedade. Esses argumentos são muitas vezes contrapostos com os da teoria, sugerindo que os defensores da teoria seriam elitistas e reducionistas ao negar a diversidade do mundo. Esse é um tema encontrado na geografia e na antropologia ao longo do século XIX e que foi ressuscitado nos últimos anos pelo pós-modernismo. Com Richard Rorty, as reivindicações em nome do pluralismo são profundas, mesmo que não sejam inteiramente consistentes, devido à sua postura agnóstica em relação à verdade. Mesmo assim, esse movimento é, no mínimo, hostil às chamadas noções fundacionalistas e essencialistas de elaboração teórica, preferindo em vez disso articular as dimensões da diversidade fora dos parâmetros estabelecidos e controlados pelos defensores da teoria. Não surpreendentemente, vozes dissidentes são identificadas por meio da inclusão de referências a gênero, raça e cultura - questões reprimidas pelos defensores da teoria na busca de uma visão simplificada e parcimoniosa de mundo. 0 melhor exemplo recente desse argumento, em interseção com a economia e a geografia, é a crítica de Gibson-Graham (1996) da economia política e seus defensores, incluindo Harvey (1989).

Nenhum movimento, seja para a teoria ou para o pluralismo, na verdade nega a ligação entre as duas extremidades da gangorra ou o íntimo conflito inerente ao raciocínio dialético. Qualquer resolução em uma extremidade ou na outra só desencadeia uma reação na outra extremidade pelo parceiro na relação dialética. Talvez a busca por resolução seja necessária para a ciência social contemporânea, dada a miopia dos defensores da teoria e a ingenuidade sem limites do pluralismo. A retórica do debate parece refletir uma escolha polarizada ou dicotômica do método das 
ciências sociais. Mas a busca de resolução também pode ser uma estratégia política no interior da instituição contenciosa da prática das ciências sociais, em vez de um verdadeiro compromisso com o saber. Seria mais honesto reconhecer a existência da gangorra, ou da relação dialética, em vez de fingir que apenas um dos lados é justificável ou a necessidade de que, no final, um lado deve dominar o outro.

De qualquer modo, é evidente que, a qualquer momento, cada um tem seu próprio papel a desempenhar no avanço do conhecimento. A esse respeito, aprecio enormemente o argumento de Siebers (1992) no sentido de que não existe uma correspondência única entre os objetos de pesquisa e as ferramentas que temos à mão para estudá-los. Assim que deixarmos para trás o mundo pré-constituído, sua ordem ideal e as ferramentas especialmente concebidas de pesquisas que sustentam esse mundo, ficaremos com uma tarefa complexa de formar conhecimento em contextos específicos. Não faz sentido se manter preso a uma metodologia ideal quando precisamos de ambos os lados da gangorra para (re) construir uma versão do mundo (para ver uma declaração anterior seguindo essa linha, ver CLARK, 1985). Em resposta a uma pergunta sobre a verdade de Rorty e o pragmatismo de Pierce, Putnam (1994, p. 63) observou que é preciso "reconhecer que, embora a verdade seja incerta, qualquer verdade digna desse nome tem de ser sujeita a testes e à discussão pública". Estabelecendo uma analogia entre a verdade científica e verdade social, Putnam diz ainda, a respeito da segunda, que "devemos testá-la e retestá-la, bem como permitir que outros a testem. Além disso, devemos constantemente discutir os métodos de verificação". Os fatos estilizados e a observação empírica são parte integrante de um teste inevitável e interminável de proposições na construção do conhecimento social ${ }^{8}$.

\section{Diálogo próximo como criação de mundos}

Até aqui argumentei que argumentos exclusivos apresentados em favor e contra observações empíricas em relação a fatos estilizados são equivocados. 0 que está implícito nestes argumentos é uma escolha absoluta impossível. No entanto, resta uma questão acerca do diálogo próximo como um método legítimo

${ }^{8}$ Aqui deve ser evidente que meu argumento é paralelo àqueles que acreditam que a construção do conhecimento é um processo social, mantido em instituições e emoldurado por hábitos e práticas compartilhadas (ver KUHN, 1970; LATOUR, 1986). A esse respeito, sou menos entusiasta sobre o realismo crítico do que alguns de seus defensores da geografia (ver McDOWELL, 1992a). Como Baert (1996), suspeito que o realismo crítico é tão excludente e idealista quanto o positivismo, a filosofia da ciência a qual visa substituir. Obviamente, devemos reconhecer que existem muitas versões do realismo. A respeito disso, simpatizo com o realismo de Putnam, especialmente por ser vinculado a uma noção cética em relação à construção de teoria. Ver abaixo. de observação empírica. Não é necessário crer em fatos estilizados para duvidar do valor do diálogo próximo; diversos defensores da observação empírica preferem a "objetividade" dos dados secundários à aparente "subjetividade" do diálogo próximo. Na verdade, alguns críticos mais inclinados a um viés empírico parecem acreditar que o real escopo das observações empíricas é definido pelos parâmetros estruturais independentes do mundo. A implicação é evidente. $\mathrm{Na}$ melhor das hipóteses, o diálogo próximo pode ser irrelevante e, na pior, pode ser enganoso e carente de substância face à estrutura do mundo. Argumenta-se que pode ser melhor utilizar métodos de análise empírica focados em parâmetros estruturais que se harmonizem com a lógica ou ordem implícita do mundo anteriormente identificado. Novamente o mundo pré-estabelecido ressurge, pressupondo um grau de coerência e estrutura que é improvável, enquanto se presume a existência de um mundo separado de nossas interpretações e representações daquele mundo. Até mesmo alguns defensores da observação empírica acabam, sem saber, escorregando para a extremidade téorica da gangorra - sem perceber as consequências que tal troca tem em nossa imaginação.

Ao mesmo tempo, há razões para preocupação no tocante à intimidade do diálogo próximo. Ela pode ser indulgente, até mesmo isoladora, dado o conhecimento especial sugerido por confidências em comum. 0 que parece agravar a situação é que o diálogo próximo pode prometer insights singulares sobre o mundo fechado da organização setorial e de seus relacionamentos, mas constantemente acabar entregando apenas informações contaminadas por motivações suspeitas. Como é possível evitar um isolamento indulgente? É preciso disposição para nos afastarmos lentamente da gangorra em direção à teoria que os fatos estilizados implicam. De certa forma, precisamos estar simultaneamente comprometidos com os relacionamentos que são essenciais ao diálogo próximo e, ainda assim, dispostos a "trair" nossos informantes por referência ao ceticismo da teoria fria. Isso não significa (novamente) que fatos estilizados subjugados a teorias sejam o teste definitivo do diálogo próximo. Em vez disso, é necessário um freio externo ao nosso entusiasmo, um senso de ceticismo que corre nos dois sentidos: da teoria ao diálogo próximo e do diálogo próximo de volta à teoria. Nesse sentido, minha postura filosófica se assemelha muito mais ao ceticismo avaliativo e reflexivo de Hume (ver BAUER, 1995) do que talvez a desenvolvimentos pós-modernos recentes que tendem a dar ênfase à impossibilidade do saber (comparar com GIBSON-GRAHAM, 1996; RIGHTER, 
1994) ${ }^{9}$

Em relação às pesquisas recentes na geografia das finanças, o ceticismo avaliativo e reflexivo de Hume é essencial para se desenvolver um melhor entendimento do contexto local da tomada de decisões. Herdamos um corpo teórico que é ao mesmo tempo extraordinariamente idealístico acerca da eficácia dos mercados e bastante distanciado da verdadeira prática de tomada de decisões de investimento. Ambos os elementos estão abertos a críticas e disputas, conforme já sugerido no trabalho de Shleifer e seus colegas (SCHLEIFER, 1998; comparar com HOUTHAKKER; WILLIAMSON, 1996).

0 objetivo aqui não é questionar a hipótese da eficiência do mercado, mas, antes, indicar que sua aceitação disseminada levou muitos pesquisadores a ignorar a diversidade temporal e espacial de agentes e instituições. Inerente à teoria está uma expectativa de que a prática da tomada de decisões seja irrelevante frente a imperativos estruturais e competitivos. 0 processo de arbitragem deveria livrar sistematicamente o mercado dos comportamentos sub-ótimos, mantendo apenas comportamentos consistentes com o mercado (para uma declaração anterior, ver ALCHIAN, 1950). O que falta na literatura são explicações para as tendências aparentes na tomada de decisões local, para o processo de inovação de produtos em mercados "rarefeitos" (incompletos ou ausentes) e um maior entendimento sobre a interação entre os preconceitos das instituições de investimento em relação à economia urbana em toda a sua variedade. Os fatos estilizados ditos relevantes para a geografia das finanças deixam tanto a desejar em relação ao seu conteúdo que não é nenhuma surpresa que confrontar sua abstração seja um dos objetivos das pesquisas dos geógrafos (ver THRIFT, 1996). 0 diálogo próximo é útil nesse contexto devido à sua potencial riqueza de observação substantiva, à oportunidade que promete para inovação intelectual e à sua relativa independência da doutrina da eficiência do mercado. 0 diálogo próximo pode ser utilizado - como já é utilizado no setor - para documentar e averiguar a verdadeira prática da tomada de decisão em investimentos, dada a extraordinária variedade de práticas e a natureza descentralizada do comportamento do mercado (ver Greenwich Associates, 1996) ${ }^{10}$.

Embora não seja possível se dar ao luxo de ignorar a doutrina da eficiência do mercado, o diálogo próximo

${ }^{9}$ Um excelente resumo do pragmatismo filosófico, incluindo comentários clássicos e recentes, pode ser encontrado em Goodman (1995). Sunley (1996) apresenta uma discussão útil do tema relacionado à geografia econômica.

${ }^{10}$ Thrift refere-se a este tipo de construção do conhecimento como "conhecimento prático", um tipo informal de conhecimento "que é aprendido com a experiência da observação e da execução em um contexto altamente particular na interação mútua direta". É um passo necessário para a criação do "conhecimento empírico" que "não só é cumulativo, mas também sistemático e coordenado sobre vastas extensões de espaço e (tempo)" (1996:101). pode ser utilizado para motivar uma reconstrução de nosso entendimento sobre as instituições de investimento e a tomada de decisão. Isso significa, portanto, ordenar as informações coletadas em um argumento coerente, tornando-as, assim, acessíveis a outros que não compartilham do processo de diálogo próximo ou da pressuposição contra a eficiência de mercado que orienta a análise. Nesse sentido, o diálogo próximo é utilizado como a matéria-prima para uma reconceptualização do comportamento econômico. Ele depende do processo de codificação que, de acordo com Bourdieu (1990), fornece um meio de construir um panorama geral do mundo observado, criando uma ponte entre a observação local e os interesses e preocupações mais amplos, construindo, assim, um mundo, em vez de simplesmente aceitá-lo como algo já pronto, elaborado pelos teóricos. A partir da codificação, é de fato um passo curto até se chegar aos fatos estilizados. Entretanto, repare que esses fatos estilizados emergem da codificação como o produto da observação empírica do comportamento do mercado, e não porque foram simplesmente impostos em razão das pressões de certas expectativas teóricas ou necessidades analíticas. Nesse sentido, os "questionários especiais" de Kaldor ressurgem da história confrontando e conquistando os fatos estilizados subjugados a teorias que sustentam a "nova" geografia econômica.

\section{Coreografia do diálogo próximo}

Ainda resta, no entanto, uma séria acusação dirigida ao diálogo próximo: que ele é vulnerável a "erros" sistemáticos e aleatórios, uma vez que depende de os interlocutores falarem a verdade sobre si mesmos e seu setor. Para os habilidosos em elaboração de questionários e técnicas de enquete, esse tipo de vulnerabilidade pode ser contrabalançado de diversas maneiras. As respostas dos entrevistados podem ser confirmadas por meio de questões-controle disfarçadas, elaboradas para testar a veracidade dos respondentes. É possível dizer aos informantes de antemão que eles fazem parte de uma enquete maior, o que implica uma forma de validação ou confirmação envolvendo seus pares. Além disso, é possível até recompensar os informantes, ou prometer-lhes uma recompensa caso "corra tudo bem" com a entrevista. Essas e outras estratégias fazem parte da caixa de ferramentas de qualquer pesquisador que depende das opiniões dos respondentes. Entretanto, elas não imunes a erros, conforme mostra a crítica de Lewontin (1996) em relação ao estudo sobre sexualidade na América, de Laumann et 
al (1994). Pode haver perguntas que os respondentes não se sintam confortáveis em responder, bem como pode haver razões, desconhecidas pelos pesquisadores, para que certos indivíduos e até grupos inteiros forneçam, de modo sistemático, informações enganosas. Nesse sentido, o diálogo próximo é tanto uma arte quanto uma ciência ${ }^{11}$.

Embora seja relevante para minha argumentação, há ainda outra dimensão para o problema do "contar a verdade". Muitas das pesquisas nas ciências sociais baseadas em questionários presumem que aquele que detém a competência é o pesquisador e que uma elaboração apurada das questões - levando em conta antecipadamente respostas certas e erradas permite dar conta dos possíveis "erros" mencionados anteriormente. 0 que essa lógica implica é uma distribuição assimétrica de poder: metaforicamente, os cientistas sociais têm a posse das cartas e distribuemnas aos respondentes em um padrão preestabelecido, de tal forma que aos respondentes só restaria responder. Estes últimos não teriam o poder de embaralhar novamente as cartas e devolvê-las aos cientistas sociais. Pode ser que isso ocorra em questionários de opinião e talvez em entrevistas com grupos focais sobre temas preestabelecidos, mas não captura com tanta precisão a intimidade e a intriga envolvidas no diálogo próximo com o setor financeiro. Por quê? Por dois motivos. 0 primeiro é que pesquisas recentes na área de finanças deixaram evidente que poucos acadêmicos conseguem estimar o alcance da inovação intelectual nos cargos mais altos das instituições financeiras. Ao não estarem cientes disso, os acadêmicos que se envolvem mais no diálogo próximo com especialistas do setor estão vulneráveis ao obscurecimento e à ofuscação desses especialistas. Estando cientes, por outro lado, os acadêmicos tornam-se vulneráveis à sedução e à cooptação. 0 segundo motivo é que ficou igualmente evidente que o conhecimento do setor é valioso para os dois lados no diálogo próximo. Os acadêmicos que transitam entre respondentes são parte constitutiva de uma complexa teia de informações. A informação é tanto o objeto das pesquisas quanto a moeda de troca para o setor como um todo.

Entre os pesquisadores que dependem de métodos como o diálogo próximo para compreender fenômenos sociais, muitos sentem que têm uma obrigação de apenas registrar e relatar as opiniões de seus respondentes (ver EMERSON et al, 1995, sobre métodos etnográficos de trabalho de campo). A assimetria de poder sugere uma obrigação ética de dar voz às opiniões daqueles que geralmente não são membros importantes de instituições

${ }^{11}$ Um argumento muito bem elaborado por Schoenberger (1991) em sua avaliação das oportunidades e dos perigos das entrevistas corporativas para a pesquisa em geografia econômica. de autoridade. No setor financeiro, no entanto, onde o status social, a educação e o salário dos respondentes são pelo menos iguais (e às vezes significativamente maiores) aos dos pesquisadores acadêmicos, o poder é mais igualitário e disputado entre as partes do diálogo próximo. Na verdade, a possibilidade de os respondentes conseguirem deliberadamente apresentar os problemas de uma maneira benéfica a seus interesses ou aos de suas instituições - mas de uma maneira dificilmente detectada por pesquisadores acadêmicos - sugere que devemos ter cautela ao invocar qualquer obrigação ética para simplesmente registrar e relatar. Uma vez que essa possibilidade seja reconhecida, fica aparente por que críticos de versões idealizadas da ciência social, como Lewontin, têm tanto êxito; ele simplesmente questionou se é possível confiar no que nos é dito. E se não for possível, devemos ter cuidado ao afirmar a veracidade de nosso conhecimento.

Se as informações são tanto o objeto de pesquisa quanto a moeda de troca, por que é que os informantes do setor financeiro estão tão dispostos a participar do diálogo próximo? Há uma variedade de motivações possíveis. Para alguns respondentes, ser entrevistado é uma afirmação de status, uma validação externa de uma importância que pode ou não ser indício de sua verdadeira posição na empresa ou na indústria. Não é à toa que alguns respondentes exageram a importância de seus cargos e funções, em um momento dependendo do entrevistador para confirmar sua importância e, em outro, exigindo respeito para que preste auxílio na pesquisa. Também é verdade, é claro, que o conhecimento e a experiência aparentes do entrevistador (realçados antes da entrevista como parte da estratégia de ganhar acesso) também podem ser uma forma significativa de persuasão para a cooperação. Uma relação recíproca fica implícita aqui: o acesso torna-se possível por meio de um acordo informal para se trocar informações, às vezes envolvendo um processo elaborado e altamente coreografado de revelações sequenciais de que participam os dois lados do diálogo. Isso é particularmente verídico para os informantes do setor que já são experientes em entrevistas. Também é possível que o acesso seja oferecido na esperança de que o entrevistador vá repassar a versão dos demais entrevistados acerca dos eventos e circunstâncias, a importância de sua empresa e "informações" relacionadas a outros respondentes (ver ABOLAFIA, 1996).

Nesse contexto, é importante reconhecer que os entrevistados podem adotar um papel ou uma variedade de papéis no decorrer de uma entrevista. Para ilustrar, é possível identificar cinco tipos comuns de papéis em minha própria pesquisa sobre mercados financeiros. 
Em primeiro lugar, há o conversador (e examinador). 0 entrevistado inicia o diálogo de uma maneira expansiva, falando sobre o que ele/ela sabe, a atual situação do setor e a importância de pesquisas para uma melhor valorização da natureza das finanças e investimentos. Pode haver outros tópicos. Restaurantes preferidos podem ser identificados, hotéis indicados e personalidades discutidas. Em muitos momentos, a maneira expansiva do entrevistado esconde um interesse no conhecimento detido pelo entrevistador sobre o setor: quem eles conhecem e o nível de valorização que dão para símbolos aparentes de status e renda. Nesse sentido, o conversador também está testando o entrevistador. Nessa situação, o truque é simultânea e apropriadamente indicar um conhecimento e uma valorização das circunstâncias do entrevistado, sem se render aos seus charmes, o que destruiria a única e especial reivindicação da pesquisa acadêmica nossa relativa independência frente aos imperativos da economia.

Sobrevivendo ao conversador, na próxima entrevista é possível que fiquemos cara a cara com o vendedor (e comprador). Aqui o diálogo se inicia com uma rápida explosão de informações que você (o entrevistador) está procurando. Isso pode ser induzido pelo entrevistador mediante uma oportunidade prévia para definir a natureza do projeto e o tipo de informação buscada. Alternativamente, o entrevistado pode se apoderar do material providenciado pelo entrevistador antes da entrevista para demonstrar que você realmente precisa de seus conselhos. Dali em diante, fica cada vez mais difícil obter/arrancar as informações do entrevistado conforme ele/ela transita para o jogo alternativo de vender informações para o entrevistador em troca de mais informação do entrevistado. Uma vez compreendida, essa relação de troca pode ser bem prolífica, obviandose a necessidade de se trocar informações e confidências pessoais. Pode, no entanto, acabar sendo bem frustrante. 0 tipo de informação que ele/ela está procurando pode não ser o mesmo tipo que você possui. Quanto mais evidente ficar esse cenário, mais provável será que a entrevista venha a ser interrompida e encerrada prematuramente, em última instância pelo entrevistado lembrando de seus outros compromissos.

Em grande parte, tende-se a presumir que o entrevistado é representativo ou ilustrativo de sua empresa. Não é incomum, entretanto, encontrar respondentes que aproveitam a oportunidade para criticar a empresa e contestar as opiniões de outros gerentes sêniores acerca das atuais circunstâncias da empresa e do setor. Com muita frequência, o respondente exigirá garantias de que ele/ela não será citado diretamente. Tais garantias têm de ser plausíveis. Portanto, há um incentivo para que o entrevistador exagere na confidencialidade das entrevistas enquanto confere ao respondente o importante papel de contar a verdade: o derradeiro controle de realidade. De todas essas formas, o respondente nos introduz a um mundo de conspiração, silêncios e negações. Ambos os lados do diálogo próximo colaboram, então, na ficção de que o respondente é a pessoa que realmente sabe o que está acontecendo e o que está dando errado na empresa. Esse é o mundo do informante (e crítico). De muitas formas, o informante recebe bem a chance de contar o seu lado da história e espera que o seu lado da história influencie fortemente a escrita do caso. Por outro lado, também é raro que tais respondentes exijam ver a versão final. Estranhamente, eles confiam sua verdade a nós.

Há também o jogador (e inimigo): uma pessoa que é o respondente ideal, tendo em vista seu cargo na empresa; uma pessoa que compreende muito bem o que você está procurando e que está disposta a participar do diálogo próximo. Ele/ela pode fornecer novas informações e ser uma importante fonte de verificação para as informações coletadas. A virtude de tais respondentes é sua posição no setor, o fato de que eles conhecem elementos-chave do projeto e o fato de terem acesso a empresas e respondentes que não estão disponíveis ao entrevistador. 0 jogador é o negociador supremo. Isso é demonstrado pela natureza agitada da entrevista, sendo coincidentemente inserida em meio a comentários e conversas em curso com funcionários, amigos e conhecidos. Também pode ser demonstrado pela urgência da entrevista, a necessidade de expor os problemas antes de um prazo real que se aproxima (a abertura do mercado de Nova York, do de Cingapura etc.). Mas as aparências enganam. Ele/ela também pode ser o inimigo da verdade. Conforme o respondente jogador faz negócios ao telefone, calculando vantagens e desvantagens a cada lance, nossa conversa também pode ser integrada ao tabuleiro de xadrez do jogador. Para o jogador não há diferença entre nós e o resto do mundo financeiro. Embora seja lisonjeador imaginar que sejamos tão importantes assim para o jogador, o fato de ele/ela tratar todos dessa maneira, independentemente de seu relacionamento, significa que não podemos confiar em nada que nos é dito.

Por fim, há o entrevistador (e confidente): a pessoa para a qual o diálogo tem um objetivo um tanto diferente do que aquele geralmente reconhecido nos estágios iniciais da discussão com respondentes de pesquisa. Alguns presumem ingenuamente que o entrevistador é neutro, quase invisível ${ }^{12}$. Mas a prática mostra que o

${ }^{12}$ Aqui eu basicamente discordo de Lamont (1992). Em seu estudo sobre os homens da classe alta americana e francesa, ela fez esforços consideráveis para se 
gênero, sexo, idade, etnia e status podem (todos juntos ou separadamente) ter uma grande relevância ao estabelecer contato e encorajar a troca de confidências (ver PIERCE, 1995). Os entrevistadores podem ser muito habilidosos em usar sua identidade (identidades) para justificar interesses ou crenças em comum. Naturalmente, o entrevistador experiente pode "mudar" conforme o entrevistado muda, tornando-se um camaleão à serviço dos interesses de sua agenda empírica. Também é possível que uma afinidade se desenvolva e que uma entrevista se torne a porta de entrada para entrevistas posteriores e até mesmo para um relacionamento de longa duração. Pode haver verdadeiros dilemas: as informações fornecidas podem, se identificadas publicamente, comprometer as carreiras profissionais dos respondentes. Nesse contexto, os fatos estilizados de Kaldor podem se tornar uma estratégia necessária para esconder fontes enquanto se interrogam teorias.

Há outros tipos de respondentes, muitos dos quais são amigáveis e cooperativos, preocupados em ajudar em vez de obstruir a pesquisa. Entretanto, há outros (talvez em menor número) que são hostis ou extraordinariamente $\operatorname{ardilosos}^{13}$. 0 motivo de serem identificados os tipos de respondentes no diálogo próximo é simples, mas profundo. Como Lewontin, não acredito que os respondentes nos falam a verdade se a verdade for definida como observações neutras e sem compromisso com o mundo discutido. Assim como eu estou interessado em diálogo próximo como um meio de construção do mundo, os respondentes também estão comprometidos em construir mundos por meio de seus diálogos com os pesquisadores. Isso não ocorre apenas porque todas as pessoas têm seus próprios projetos de vida que requerem articulação (e encobrimento) de outros. $\mathrm{Na}$ indústria financeira, onde as informações são tanto o objeto de análise quanto a moeda de troca, os respondentes são informantes habilidosos e perspicazes. Não faz sentido negar esse fato da vida. Também não faz sentido dar as costas ao diálogo próximo, em razão da "subjetividade" dos respondentes. Em vez disso, o processo de verificação de Putnam e o

manter anônima, para ser alguém com uma "identidade profissional opaca" (p. 20). Ela acreditava que tal identidade opaca "era essencial para descontextualizar o 'gerenciamento de impressão' [estratégias] conduzida pelos homens... entrevistados" (p. 21). Ela buscou a neutralidade em um vestido comportado, em uma abordagem discreta para conversa e em um carro médio. Mas, da mesma forma, ela era uma professora de Princeton (adjunta), uma profissional no início de seus trinta anos, habituada com a língua e a cultura francesa, e uma pessoa de grande capacidade intelectual. Ela estava realmente anônima? Será que ela realmente controlava as conversas como alegava? Duvido que qualquer respondente experiente do setor financeiro seria enganado dessa maneira.

${ }^{13}$ Eu não selecionei para entrevistar qualquer um que seja suspeito de traição ou que acredite ser responsável por ações antiéticas ou moralmente erradas. Mesmo assim, acontece. Em tais ocasiões, fica-se impressionado pela natureza do jogo: os assuntos discutidos e os temas não reconhecidos à espreita logo abaixo da superfície. Muitas vezes parece que o entrevistado tem a intenção de demonstrar sua razoabilidade, caridade e consideração como se ele ou ela pudesse nos convencer de sua normalidade. Mas, igualmente, fica-se desconfiado, procurando sutis sinais de astúcia e maldade. A este respeito, o relato de Alice Kaplan de sua entrevista (1993, p. 189-90) com um simpatizante nazista francês é pertinente para a questão. ceticismo de Hume devem ser reconhecidos como as respostas mais apropriadas para um mundo que é feito e refeito pelas interpretações de nós mesmos e de nossos respondentes.

\section{Implicações e Conclusões}

A geografia econômica é uma área em expansão nos dois lados da fronteira disciplinar: economistas e geógrafos estão falando cada vez mais sobre questões afins, se não de formas similares ou até mesmo para os mesmos propósitos. Pode ser que, na verdade, haja muitas sobreposições e semelhanças. Pode ser que qualquer busca por diferenças reais possa se afundar na notável variedade de estratégias de pesquisa no interior das duas disciplinas. Nesse caso, embora seja possível criticar Krugman e seus colegas do National Bureau of Economic Research e do Center for Economic Policy Research por sua abstração estilizada e inclinação para determinados métodos analíticos, tentei sugerir que tais críticas são mais comuns do que se supõe. 0 diálogo próximo não funciona como os modelos convencionais de pesquisa nas ciências sociais e, se devemos levá-lo a sério, e assim ganhar distanciamento da economia geográfica de Krugman, há algumas implicações importantes que devem ser reconhecidas.

Para começar, o diálogo próximo nega o princípio mais óbvio do positivismo: a suposta diferença entre objetividade e subjetividade. Também vai além das supostas distinções profundas entre métodos de pesquisa quantitativa e qualitativa - não se pode presumir, igualmente, que a pesquisa qualitativa seja complementar à pesquisa quantitativa (ver MORROW; BROWN, 1994). Estando focado na derivação do conhecimento por meio de relacionamentos sociais, o diálogo próximo está muito relacionado às pesquisas feministas contemporâneas. 0 diálogo próximo, como o feminismo de Stanley \& Wise (1993), inicia-se com o pessoal, baseia-se em relacionamentos sociais contestados e exige um nível de reflexividade que é incompatível com a ciência social convencional ${ }^{14}$. No entanto, não é incompatível com a prática real da tomada de decisões financeiras dentro e fora de instituições financeiras. Como tentei sugerir, o diálogo próximo é um ingrediente essencial do setor; a troca de informações (incluindo interpretações individuais de dados comuns) e o gerenciamento de redes de informação (especialmente aquelas que dependem de reciprocidade) são processos sociais vitais que são ignorados apenas em prejuízo das instituições que não os valorizam. Essas observações

${ }^{14 E ́}$ claro que existem muitas versões de feminismo dentro e fora da geografia (comparar McDOWELL, 1992b a BONDI 1997). 
vão direto ao encontro da indústria financeira e dos padrões identificados por Shleifer e seus colegas.

Se há ligações significativas e importantes a serem feitas entre o diálogo próximo e a metodologia feminista contemporânea, também há similaridades a serem reconhecidas entre o diálogo próximo e a assim chamada literatura das finanças comportamentais. De acordo com Thaler (1994), os fatos estilizados que têm dominado as teorizações econômicas e a economia financeira em particular são inteiramente não justificados - a evidência empírica não dá suporte nem mesmo a suposições rudimentares feitas por teóricos do mercado eficiente acerca da racionalidade e atitudes dos agentes frente a riscos e incertezas. 0 diálogo próximo é um meio de compreender melhor a verdadeira prática da tomada de decisões. É um meio de reintroduzir a geografia (e a história, a sociologia, etc.) em um mundo que parece ter sido inventado para o benefício dos teóricos. Por meio do diálogo próximo, nosso objetivo deve ser reintroduzir a profunda textura das circunstâncias locais, incluindo crime e corrupção (ver CLARK, 1998), circunstâncias essas que têm sido deliberadamente evitadas por teóricos mais preocupados com a simplicidade do que com a diversidade da vida econômica. Ao mesmo tempo, é importante reconhecer uma lição das pesquisas feministas contemporâneas: a subjetividade é sempre situada, mesmo se a própria prática da tomada de decisões reconceptualiza - e, portanto, refaz - o mapa dos serviços financeiros (ver GAGNIER, 1991, para um estudo interessante acerca da identidade no século XIX que defende esse ponto).

Há muitos economistas que estão igualmente em dúvida sobre o valor dos fatos estilizados e sobre os métodos de teorização relacionados, preferindo métodos de pesquisa que enfatizam observações empíricas de comportamentos reais em tempos e locais específicos. Com respeito a isso, a disputa sobre os fatos estilizados em contraposição com as observações empíricas tem menor relação com a prática disciplinar e maior relação com a interação tensa e disputada entre duas abordagens opostas, mas inerentemente conectadas, para a construção do conhecimento nas ciências sociais e em outras áreas. A metáfora utilizada aqui para ilustrar essa conexão é de John McDowell (1994): eu sugeri que os fatos estilizados subjugados a teorias ocupam uma ponta da gangorra, e que as observações empíricas, a outra. Como em uma gangorra, deslizamos de um lado para o outro, tendo nossa escolha do ponto de partida em parte determinada pela nossa tradição disciplinar, assim como pelo nosso interesse na inovação, em vez da coerência da pesquisa. Outras metáforas podem ser úteis (comparar com BARNES, 1996). Utilizei uma ordem espacial imaginária que concede às duas abordagens seu devido valor, ao mesmo tempo em que sugere que a nossa localização inicial em cada ponta da gangorra é uma consequência da tradição herdada.

Segundo minha avaliação, o diálogo próximo é um meio muito útil de se promover inovação conceitual e teórica. Nos últimos anos, geógrafos e alguns economistas têm utilizado essa estratégia com bastante êxito, tornando-se mais sensíveis tanto aos componentes espaciais quanto aos componentes temporais na turbulenta economia global. Tendo em vista o sucesso dessa estratégia e as recompensas para inovações conceituais, os fatos estilizados e os métodos de pesquisa relacionados podem abrir caminho para nosso fascínio com a diferenciação espacial. Não é de se surpreender, portanto, que a aceitação, na geografia, da economia geográfica de Paul Krugman tenha sido relativamente limitada. Embora não se duvide de sua habilidade e de seu aparente êxito em extrair novos insights de problemas antigos (a regra de "rank-size", aglomeração e afins), duvidamos da significância de seus fatos estilizados. Para muitos, convencidos da singularidade e do distanciamento do diálogo próximo, qualquer passo da codificação rudimentar em direção ao comprometimento com a outra ponta da gangorra seria um anátema à prática atual. Entretanto, a lealdade dos geógrafos a uma ponta da gangorra carrega consigo consideráveis problemas, dentre os quais a consequente inabilidade de tratar questões políticas e de regulação contemporâneas de uma forma abrangente. Nesse quesito, os economistas parecem ter problemas mais simples e soluções mais evidentes, enquanto muitos geógrafos parecem ter apenas mais detalhamento.

A partir da análise anterior sobre os laços de intimidade e intriga que geralmente acompanham o diálogo próximo, deve ficar claro que estou incerto quanto ao estatuto de afirmações de verdade absoluta ou quanto a afirmações factuais profundas que fluem de tais encontros. No entanto, eu não duvido do valor do diálogo próximo. Apenas porque sempre há um uma dimensão mais intimista em tais encontros, não significa que o que é obtido esteja significativamente contaminado. É sempre necessário ser cauteloso em relação à integridade das informações, tanto as informações formais quanto as informais. O problema do diálogo próximo é que há uma falta de referências cruzadas com outros casos. Embora seja uma estratégia poderosa para se interrogar as asserções dos fatos estilizados, raramente é adequado como uma estratégia para se construir coalizão. Enquanto os fatos estilizados podem ser compartilhados por analistas que literalmente estão sentados na frente de seus computadores, qualquer tentativa de realizar 
referências cruzadas e de integrar conjuntos de casos separados de pesquisadores individuais se torna um problema de ação coletiva. A pluralidade inerente ao diálogo próximo é uma ameaça à construção de coalizões intelectuais que, em última instância, afetarão ações políticas e escolhas regulatórias. Nesse quesito, uma melhor valorização dos fatos estilizados de Kaldor pode ser um ingrediente necessário em qualquer estratégia que tenha como objetivo integrar os diversos resultados dos diálogos próximos dos geógrafos.

Não defendo, portanto, uma inversão na estratégia empírica, nem defendo outra rodada de abstração teórica. É preciso, no entanto, encontrar maneiras de colher benefícios progressivos da atual obsessão que os geógrafos têm pelo diálogo próximo. Há um verdadeiro risco de que a intriga e a intimidade do diálogo próximo desloque nosso senso de comprometimento coletivo. Não só poderemos ser seduzidos pela coreografia do diálogo próximo como também poderemos ser seduzidos pelas circunstâncias especiais de estudos de caso separados. 0 desafio, politicamente falando, é levar ao mundo da política e da regulação um sentido de diferença (conforme sugerido pelo diálogo próximo) e um sentido de comprometimento com o bem-estar coletivo que apenas pode ser possível por meio de fatos codificados, até mesmo estilizados, acerca do mundo. Ressuscitar o comprometimento com a reflexão intelectual coletiva é uma tarefa essencial para a geografia econômica, tarefa esta que compartilhamos com outros que estão, de maneira semelhante, preocupados em superar os efeitos debilitantes de identidades fragmentadas e lealdades apartadas.

\section{Agradecimentos}

O apoio para este artigo foi providenciado pelo Australian Housing and Urban Research Institute e pelo Australian Research Council, como parte de um projeto maior sobre fundos de pensão e investimento urbano. Foi apresentado pela primeira vez em um painel organizado por Amy Glasmeier no Annual Meeting of the Association of American Geographers, em abril de 1997, na cidade de Fort Worth, Texas. Agradeço a Mike Berry, que apoiou e encorajou o projeto, bem como a Maryann Feldman, Meric Gertler e Ben Harrison, que fizeram comentários no rascunho inicial. Subsequentemente, muito me auxiliaram os comentários de John Agnew, Trevor Barnes, Philip Pettit, Amanda Root, Eric Sheppard, Nigel Thrift e os de quatro outros pareceristas. Também agradeço a Jan Magee, que, como de costume, forneceu uma excelente assistência. Apenas este autor é responsável pelas visões e opiniões aqui expressadas. 


\section{Referências}

ABOLAFIA, Mitchell. (1996). Making Markets: Opportunism and Restraint on Wall Street. Cambridge: Harvard University Press.

ALCHIAN, Armen. (1950). Uncertainty, Evolution and Economic Theory. Journal of Political Economy 58:211-22.

ARTHUR, W. Brian. (1994). Increasing Returns and Path Dependency in the Economy. Ann Arbor: Univer-sity of Michigan Press.

AUDRETSCH, D. B.; FELDMAN, Maryann. (1996). Knowledge Spillovers and the Geography of Innovation and Production. American Economic Review 86:630-40.

BAERT, Patrick. (1996). Realist Philosophy of the Social Sciences and Economics: A Critique. Cambridge Journal of Economics 20:513-22.

BAIER, Annette. (1994). Moral Prejudices. Cambridge: Harvard University Press.

BARNES, Trevor. (1996). Logics of Dislocation: Models, Metaphors, and Meanings of Economic Space. New York: Guilford Press.

BARRO, Robert; SALA-I-MARTIN, Xavier. (1995). Economic Growth. New York: McGraw-Hill.

BASU, S.; FERNALD, J. G. (1997). Returns to Scale in U.S. Production: Estimates and Implications. Journal of Political Economy 105:249-83.

BAUMOL, William. (1991). Towards a Newer Economics: The Future Lies Ahead! Economic Journal 101:1-8.

BONDI, Liz. (1997). In Whose Words? On Gender Iden-tities, Knowledge and Writing Practices. Transactions of the Institute of British Geographers NS22:245-58.

BOURDIEU, Pierre. (1990). In Other Words: Essays towards a Reflexive Sociology. Cambridge: Polity Press.

CLARK, Gordon L. (1985). Judges and the Cities. Chicago: University of Chicago Press.

(1993). Pensions and Corporate Restructuring in American Industry: A Crisis of Regulation. Baltimore: Johns Hopkins University Press.

(1994). Strategy and Structure: Corporate Restructuring and the Scope and Characteristics of Sunk Costs. Environment and Planning A 25:9-32.

(1997). Pension Funds and Urban Investment: Four Models of Financial Intermediation. Environment and Planning A 28:1297-1316.

(1998). The Anatomy of Corruption: The Practice of Pension Fund Investment Decision Making. Environment and Planning A 29:(forth-coming).

; Gertler, Meric S.; and Whiteman, John. (1986). Regional Dynamics: Studies in Adjustment Theory. London: Allen and Unwin.

DOW, Sheila. (1997). Mainstream Economic Method. Cambridge Journal of Economics 21:73-93.

EMERSON, Robert M.; FRETZ, Rachel; SHAW, Linda L. (1995). Writing Ethnographic Fieldnotes. Chicago: University of Chicago Press.

FAMA, Eugene. (1970). Efficient Capital Markets: A Review of Theory and Empirical Evidence. Journal of Finance 25:383-417.

1991. Efficient Capital Markets: II. Journal of Finance 46:1575-1618.

FELDMAN, Maryann; FLORIDA, Richard. (1994). The Geographical Sources of Information: Techno-logical Infrastructure and Product Innovation in the United States. Annals of the Association of American Geographers 84:210-29.

GAGNIER, Regenia. (1991). Subjectivities: A History of Self-Representation in Britain, 1832-1920. Oxford: Oxford University Press.

GEERTZ, Clifford. (1983). Local Knowledge. New York: Basic Books. 
GERTLER, Meric S. (1993). Implementing Advanced Manufacturing Technologies in Mature Industrial Regions: Towards a Social Model of Technological Production. Regional Studies 27:259-78.

(1996). Worlds Apart: The Changing Market Geography of the German Machinery Industry. Small Business Economics 8:87-106.

GIBSON-GRAHAM, J. K. (1996). The End of Capitalism (As We Knew It): A Feminist Critique of Political Economy. Oxford: Blackwell.

GOODMAN, Russell B., ed. (1995). Pragmatism: A Contemporary Reader. London: Routledge.

GREENWICH ASSOCIATES. (1996). New Paradigm, New Potency. Greenwich, CT: Greenwich Assoc.

HAHN, Frank. (1991). The Next Hundred Years. Economic Journal 101:47-50.

HARRISON, Bennett; KELLEY, Maryellen; GANT, Jon. (1996). Innovative Firm Behavior and Local Milieu: Exploring the Intersection of Agglomeration, Firm Effects, and Technological Change. Economic Geography 72:233-58.

HARVEY, David. (1989). The Condition of Postmodernity. Oxford: Blackwell.

(1996). Justice, Nature and the Geography of Difference. Oxford: Blackwell.

HOUTHAKKER, Henrik; WILLIAMSON, Chris. (1996). The Economics of Financial Markets. Oxford: Oxford University Press.

KALDOR, Nicholas. (1985). Economics without Equilibrium: The Arthur Okun Memorial Lectures. New York: M. E. Sharpe.

KAPLAN, Alice. (1993). French Lessons. Chicago: University of Chicago Press.

KRUGMAN, Paul. (1991). Geography and Trade. Cambridge: MIT Press.

. (1996). The Self-Organizing Economy. Oxford: Blackwell.

KUHN, Thomas. (1970). The Structure of Scientific Revolutions. Chicago: University of Chicago Press.

LAMONT, Michele. (1992). Money, Morals, and Manners: The Culture of the French and the American Upper-Middle Classes. Chicago: University of Chicago Press.

LATOUR, Bruno. (1986). Science in Action. Milton Keynes, U.K.: Open University Press.

LAUMANN, Edward; Gagnon, J.; Michael, J. R.; and Michaels, S. (1994). The Social Organisation of Sexuality. Chicago: University of Chicago Press.

LEWONTIN, Richard C. (1995). Sex, Lies, and Social Science. New York Review of Books April 20, 24-29.

LEYSHON, Andrew; THRIFT, Nigel; PRATT, Jonathan. (1998). Reading Financial Services. Society and Space (forthcoming).

MARTIN, Ron; SUNLEY, Peter. (1996). Paul Krugman's 'Geographical Economics' and Its Implications for Regional Development Theory: A Critical As-sessment. Economic Geography 72:259-92.

and (1997). Slow Convergence? The New Endogenous Growth Theory and Regional Development. Mimeo. University of Cambridge.

MCDOWELL, John. (1994). Mind and World. Cambridge: Harvard University Press.

MCDOWELL, Linda. (1992a). Valid Games? A Response to Erica Schoenberger. The Professional Geographer 44:21215.

(1992b). Doing Gender: Feminism, Feminists and Research Methods in Human Geography. Transactions of the Institute of British Geographers NS17:399-416.

(1997). Capital Culture. Oxford: Blackwell.

MORROW, Raymond; BROWN, David. (1994). Critical Theory and Methodology. London: Sage Publications.

NELSON, Richard. (1995). Recent Evolutionary Theoriz-ing about Economic Change. Journal of Economic Literature 33:48-90. 
NUSSBAUM, Martha C. (1990). Love's Knowledge: Essays on Philosophy and Knowledge. Oxford: Oxford Uni-versity Press.

(1996). Poetic Justice: The Literary Imagination and Public Life. Boston: Beacon Press.

PALMER, K.; Oates, WARREN E.; PORTNEY, Paul. (1995). Tightening Environmental Standards: The Benefit-Cost or The No-Cost Paradigm. Journal of Economic Perspectives 9:119-32.

PIERCE, Jennifer L. (1995). Gender Trials: Emotional Lives in Contemporary Law Firms. Berkeley: University of California Press.

PORTER, Michael; VAN DER LINDE, Claus. (1995). Towards a New Conception of the Environment-Competitiveness Relationship. Journal of Economic Perspectives 9:97-118.

PUTNAM, Hilary. (1992). Renewing Philosophy. Cambridge: Harvard University Press.

(1994). Between the New Left and Judaism. In The American Philosopher, ed. by G. Borradori, pp. 55-69. Chicago: University of Chicago Press.

RIGHTER, William. (1994). The Myth of Theory. Cambridge: Cambridge University Press.

ROMER, David. (1994). The Origins of Endogenous Growth. Journal of Economic Perspectives 8:3-22.

SAYER, Andrew. (1995). Radical Political Economy: A Critique. Oxford: Blackwell.

SCHOENBERGER, Erica. (1991). The Corporate Interview as a Research Method in Economic Geography. The Professional Geographer 43:180-89.

(1992). Self-Criticism and Self-Awareness in Re-search: A Response to Linda McDowell. The Pro-fessional Geographer 44:215-18.

(1996). The Cultural Crisis of the Firm. Oxford: Blackwell.

(1998). Discourse and Practice in Human Geography. Progress in Human Geography (forthcoming).

SHLEIFER, Andre. (1998). Market Inefficiency. Clarendon Press: Oxford (forthcoming).

SIEBERS, Tobin. (1992). Morals and Stories. New York: Columbia University Press.

STANLEY, Liz; WISE, Sue. (1993). Breaking Out Again: Feminist Ontology and Epistemology. London: Routledge.

STORPER, Michael. (1989). The Transition to Flexible Specialization in the U.S. Film Industry: The Division of Labour, External Economies, and the Crossing of Industrial Divides. Cambridge Journal of Economics 13:273-305.

(1991). The Limits to Globalisation: Technology Districts and International Trade. Economic Geography 67:6093.

and Salais, Robert. (1997). Worlds of Production: The Action Frameworks of the Economy. Cambridge: Harvard University Press.

SUNLEY, Peter. (1996). Context in Economic Geography: The Relevance of Pragmatism. Progress in Human Geography 20:338-55.

THALER, Richard, ed. (1993). Advances in Behavioral Finance. New York: Russell Sage Foundation.

THRIFT, Nigel. (1996). Spatial Formations. London: Sage.

WEBBER, Michael; RIGBY, David. 1996. The Golden Age Illusion: Rethinking Postwar Capitalism. New York: Guilford Press.

WOOLLEY, Francis. (1993). The Feminist Challenge to Neoclassical Economics. Cambridge Journal of Economics 17:485-500. 